\title{
Erratum to: Artifact level produced by different femoral head prostheses in CT imaging: diamond coated silicon nitride as total hip replacement material
}

\author{
Simone P. Rodrigues $\cdot$ José M. Paiva $\cdot$
}

Silvia De Francesco $\cdot$ M. Amaral ·

Filipe J. Oliveira $\cdot$ Rui F. Silva

Published online: 11 November 2012

(C) Springer Science+Business Media New York 2012

\section{Erratum to: J Mater Sci: Mater Med}

DOI 10.1007/s10856-012-4778-0

The original version of this article unfortunately contained a mistake. One of the author's name and affiliation was incorrect. The authors have subsequently informed us of their wish to amend the details. The correct name and affiliation is given below.

The online version of the original article can be found under doi:10.1007/s10856-012-4778-0.

S. P. Rodrigues $(\bowtie) \cdot$ F. J. Oliveira · R. F. Silva

CICECO, Department of Ceramics and Glass Engineering,

University of Aveiro, 3810-193 Aveiro, Portugal

e-mail: simonerodrigues@ua.pt

J. M. Paiva $\cdot$ S. De Francesco

Higher School of Health, University of Aveiro,

3810-193 Aveiro, Portugal

M. Amaral

$13 \mathrm{~N}$ - Physics Department, University of Aveiro,

3810-193 Aveiro, Portugal 